\title{
Editorial by Günter Köck, Valerie Braun and Arne Arnberger
}

Austria is one of the first member states to become involved in the MAB programme. In 1973, just two years after the start of the MAB programme, the Austrian National MAB Committee was established at the Austrian Academy of Sciences (ÖAW), based on an agreement with the Federal Ministry of Science and Research and charged with the task of controlling and coordinating MAB research. From the start, the Committee was endowed with a separate research budget. This budget allows the Committee not just to identify research gaps, but to fill them with appropriate research projects. The National Committee monitors Austrian research, analyses research needs, formulates new research strategies and stimulates as well as funds research projects. Overall, the MAB National Committee has funded countless research projects in nearly five decades of its existence. In addition, the Committee has funded several activities of the MAB programme, e. g. the MAB Young Scientist Awards and the publication of three MAB Biannual Activity Reports (Website of the Austrian MAB National Committee: http://www.biosphaerenparks.at/).

Almost two years ago, the MAB Committee discussed possible activities to celebrate the $50^{\text {th }}$ Anniversary of UNESCO's Man and the Biosphere (MAB) Programme in style. Given the MAB Committee's strong commitment to research in and for biosphere reserves (BRs), and not least because of the extensive expertise of the Austrian scientific community in mountain research, the decision quickly became clear: The Austrian MAB National Committee will organize and finance a special issue on Biosphere Reserves in Mountain Regions in the renowned scientific journal ecomont. The call for proposals was very successful: the special issue contains 16 articles from four out of five MAB regions.

Several key messages can be derived from the articles. Some articles deal with long-term changes in the MAB programme and its World Biosphere Reserve Network (WNBR): Price et al. analyse the development of mountain research in the MAB programme over the 50 years of its existence, while Thomsen et al. look at the transformation of the BR network in the USA. Knaus et al. analyse the output of two decades of research in the Swiss Entlebuch BR. In the article by Jungmeier et al., a large number of authors deal with the historical development, the current status and the future perspective (especially in relation to the implementation of the SDGs) of BRs in Germany, Austria and Switzerland. These articles highlight the successful constant evolution and adaptation (e. g. Seville Strategy, Madrid Action Plan, Lima Action Plan) of the MAB programme over the last 50 years in response to changing global challenges. Residents and stakeholders seem to see many advantages in the existence of a BR and benefit from its ecosystem services (Eder \& Arnberger; Pantic et al.). However, there are many local and global factors that alter and threaten BRs, including climate change, depopulation, over-tourism, illegal construction, land abandonment, and lack of legal support (Di Lonardo \& Cinocca; Botha et al.; Huber et al.; Ibisch et al.; Mansilla-Quinones et al.; Odar et al.; Pantic et al.). BRs therefore need to adapt, require capacity building and need experienced management with sufficient financial and human resources to meet these challenges (Thompson et al.).

Residents certainly play a key role in the success of a BR. Some BRs have well-established participation processes and are well anchored and accepted regionally, while others have problems, for example, in terms of acceptance by indigenous people or youth involvement (Thompson et al.). BRs would do well to strive to better integrate previously marginalized / underrepresented groups (Thompson et al.). An important task for the future is certainly to invite more young people to participate in the implementation of BRs and so train the next generation of leaders (Mansilla-Quinones et al.; Odar et al.). Care must also be taken to ensure that local people develop a bond with their own BR (Eder \& Arnberger; Mansilla-Quinones et al.) and identify with the MAB programme and its goals (Thompson et al.).

Scientific research will be a critical success factor in the future to support BR management and transformation processes (Knaus et al.). BRs are taking the lead in transformation, but adequately implementing all SDGs may overwhelm BR management (Jungmeier et al.). The articles in the special issue contain many best practices, references, and recommendations to ensure the long-term sustainability and successful management of BRs.

The Austrian MAB National Committee is pleased to present this Special Issue on Biosphere Reserves in Mountain Regions to the international MAB community on the occasion of the $50^{\text {th }}$ anniversary of this outstanding programme. Last but not least, this issue should also be understood as a contribution to the re-launch of the World Network of Mountain Biosphere Reserves. The Austrian MAB Committee, as one of the longest existing national MAB committees, has contributed to the evolvement of this UNESCO flagship programme for almost 50 years and is committed to its continued support for the future.

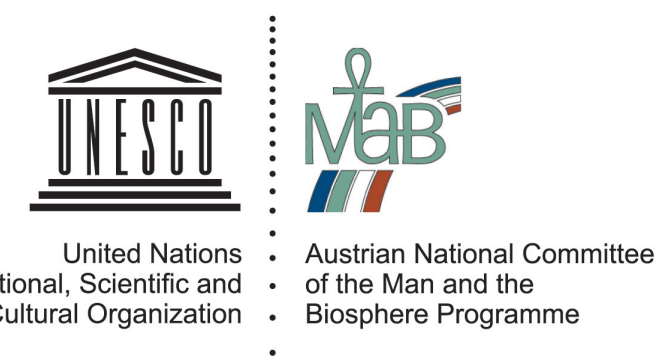

